\title{
Successful maternal and fetal outcome in patients with Takayasu arteritis: two case reports of Type I and Type IV in stage 2
}

\author{
Rekha Upadhya*, Vidyashree G. Poojari, Muralidhar V. Pai, Jayaraman Nambiar
}

Department of Obstetrics and Gynecology, Kasturba Medical College, Manipal, Karnataka, India

Received: 12 December 2017

Accepted: 08 January 2018

\section{*Correspondence:}

Dr. Rekha Upadhya,

E-mail: rex2000@ rediffmail.com

Copyright: (C) the author(s), publisher and licensee Medip Academy. This is an open-access article distributed under the terms of the Creative Commons Attribution Non-Commercial License, which permits unrestricted non-commercial use, distribution, and reproduction in any medium, provided the original work is properly cited.

\begin{abstract}
Takayasu's arteritis, is a rare, chronic, idiopathic, inflammatory disease of the large arteries, primarily involves the aorta, its main branches as well as the coronary and pulmonary arteries. It is mostly seen among women with child bearing age group (80\%). During pregnancy, the increased intravascular volume impair circulation and exacerbate aortic regurgitation, hypertension, and congestive heart failure. Hypertension is one of the serious complication that can develop, leading to intrauterine growth restriction, maternal heart failure, and fetal haemorrhage and during postpartum period.
\end{abstract}

Keywords: Angiogram, Hypertension, Pregnancy, Renal artery stenosis, Takayasu arteritis (TA)

\section{INTRODUCTION}

Takayasu arteritis, synonymously known as "pulseless disease" or "young female arteritis" or aortic arch syndrome or nonspecific aortoarteritis, is a rare chronic granulomatous inflammatory disease of the aorta and/or its major branches affecting mostly vertebral, carotid, subclavian, iliac and renal arteries. ${ }^{1,3}$ Clinical features are related to the affected artery: subclavian and iliac arteries involvement present with limb claudication; carotid involvement may induce vertigo and lipothymy; renal arterial lesions are associated with arterial hypertension; while some patients can progress to aortic insufficiency and congestive heart failure. Most affected patients are women under the age of $<40$ and it seems to be more common in Asians and their descendants, with a worldwide annual incidence estimated to be between 1.2 and $2.6 /$ million. The compiled data indicate that the disease does not worsen during pregnancy, but complications such as intrauterine growth restriction, fetal death, hypertension, heart failure and aneurysm rupture have been described. ${ }^{4,5} \mathrm{We}$ report here the maternal and fetal outcomes of 2 patients with TA with Type I and Type IV stage 2 disease followed at our tertiary care centre.

\section{CASE REPORT}

We describe a 25-year-old, primigravida referred to our hospital at 23 weeks with complaints of pain and weakness of both the upper limbs for one week started at 16 weeks of gestation at a peripheral hospital. On examination she was found to have absent pulse on the left upper arm and blood pressure was not recordable on the same side. Investigations showed raised ESR of 120 $\mathrm{mm}$, ANA 12.61(<20), rheumatoid factor $1.0(0-20)$, ASO titre 265 (0-200). Doppler of both upper limb complete occlusion of brachial and axillary arteries on the left side and sluggish flow in the distal vessels on the right side. MR Angiogram showed narrowing of bilateral subclavian arteries. Renal artey Doppler was normal. Trivial MR on maternal ECHO seen. Diagnosis of Takayasu Arteritis with Type 1 stage 2 was made based on these investigations and examination. She was started 
on Inj. Heparin 5000 IU. She had regular antenatal check up with interval growth scans and blood pressure monitoring which were within normal limits at her native place. She was referred back at 37 weeks for safe confinement to our hospital. She was continued on injection heparin. Her left upper limb radial, brachial, carotid pulses were not felt. Right upper limb with feeble radial pulse and normal brachial and carotid pulse felt. Blood pressure on the left upper limb 110/70mmHg and right upper limb with $120 / 80 \mathrm{~mm} \mathrm{Hg}$. There was no murmur or carotid bruit on cardiovascular examination. Delivered by emergency LSCS under spinal anaesthesia, in view of cephalopelvic disproportion to a live male baby of $3340 \mathrm{gm}$. Postoperatively mild postpartum haemorrhage was managed with tablet misoprostol $800 \mathrm{mcg}$ and injection tranexamic acid, other oxytocics were avoided. Heparin was restarted and then changed over to warfarin before discharge. There was no high blood pressure recording in post-partum period.

\section{Case report 2}

A 25-year-old Gravida 2 Para 1 with previous LSCS at 37 weeks gestation referred to our hospital with diagnosis of Takayasu arteritis type 4 stage 2 with renal and vertebral artery stenting in the first pregnancy. She was previously referred here one year back with young hypertension for evaluation with left arm blood pressure of 180/100 $\mathrm{mmHg}$, absent right arm pulse and bruit present in the left carotid and abdominal aorta and diagnosed

Takayasu arteritis at Cardiology Department in our hospital. She was on Wysolone $40 \mathrm{mg}$ following renal and vertebral artery stenting in 2014 until 28 weeks of gestation. Her diagnosis was made on the basis of arterial Doppler of the upper limb showing complete stenosis of right subclavian and partial stenosis of left subclavian artery. Angiography showing renal ostial stenosis of $90 \%, 100 \%$ right subclavian and $70 \%$ left subclavian stenosis. She underwent bilateral renal artery stenting and left vertebral artery stenting as right vertebral artery was completely occluded. She was advised to continue wysolone $40 \mathrm{mg}$ and Ecosprin. On admission at 37 weeks gestation revealed absent radial, brachial pulse on the right upper limb and absent radial pulse on the left hand. Other peripheral pulses were felt. Blood pressure on both upper limbs could not be measured. Right thigh blood pressure measured 120/80mm Hg. She underwent emergency caesarean section under spinal anaesthesia in view of PROM and Meconium liquor in the first stage of labor. Delivered a live female baby of $2900 \mathrm{gm}$. Postopratively increased blood pressure was managed with antihypertensives.

Renal artery Doppler was normal. Thromboprophylaxis was started along with aspirin at discharge. During current pregnancy she was on ecosprin as per cardiologist advice. She tolerated this pregnancy well. Underwent elective LSCS with sterilisation. Delivered $2860 \mathrm{gm}$ female baby. Advised to continue ecosprin and regular followup.

\section{DISCUSSION}

Takayasu Arteritis was first described in 1908 by two Japanese ophthalmologists, Takayasu M and Onishi, who observed retinopathy in the absence of peripheral pulses. ${ }^{6}$ The cause is unknown, but it seems to be related to autoimmunity, sex hormones (more common in young females), and genetics (demonstrated by the predisposition of the human leukocyte antigen: HLA BW52). ${ }^{7}$ Based on signs and symptoms, inflammatory markers, and arteriography demonstrating aortic stenosis and of its branches diagnosis is made. Pregnancy does not interfere on disease progression, although hypertensive complications such as preeclampsia and exacerbation of chronic hypertension, and fetal complications such a restriction of intrauterine growth, abortion, and fetal death have been reported in $60 \%$ to $90 \%$ of the cases.

Uncontrolled hypertension and aorta, iliac arteries involvement are associated with high incidence of restricted uterine growth. Pregnancy is a state favorable to the disease..$^{8-10}$ Early onset hypertension is the commonest complication. Preeclampsia constitute main maternal complications resulting intrauterine growth restriction. Hypertension, due to reduction in elasticity and narrowing of the aorta and its branches, besides abnormalities in the function of the aortic and carotid baroreceptors function. ${ }^{11}$

Occlusive and stenotic lesions might require revascularization by percutaneous angioplasty, use of endoprosthesis, or surgical correction. ${ }^{12}$ Disease progression typically occurs in various stages from acute inflammatory arteritis to lymphocytic infiltration, intimal thickening, elastic tissue destruction, fibrosis and patchy luminal narrowing of arteries associated with disease progression. Depends on Angiographic classification there are five types based on the involvement arteries. Type I involves branches of aortic arch, Type IIa ascending aortaaortic arch and its branches, Type IIb involves Type IIa and thoracic descending aorta, Type III thoracic descending aorta, abdominal aorta, renal arteries or combination, Type IV abdominal aorta, renal arteries or both, Type $\mathrm{V}$ involves entire aorta and its branches. Takayasu Arteritis progresses through three stages.

- $\quad$ Stage 1 (prevasculitic systemic stage): Constitutional symptoms like fatigue, malaise, giddiness, fever

- Stage 2 (vascular inflammatory stage): Stenosis, aneurysms and vascular pain (carotidynia)

- $\quad$ Stage 3 (burned-out stage): Fibrosis and generally associated with remission.

Takayasu arteritis in pregnancy is a high-risk pregnancy. Normal BP at the beginning of prenatal care associated with better outcome. 
In group I and IIa vaginal delivery may be indicated.12. Management of pregnant patient with Takayasu arteritis does not differ from a any pregnant patient. Strict control of blood pressure mode of delivery should be planned. Epidural anaesthesia provides stable haemodynamics and pain relief during labour. Second stage of labour to be cut short by instrumental delivery. ${ }^{13}$ In groups IIb and III, one should prefer cesarean section, since the increased blood volume and blood pressure observed during uterine contractions as well as the increased cardiac output observed during labor may lead to cardiac decompensation. ${ }^{14}$ For LSCS epidural anaesthesia or general anaesthesia preferred because regional anaesthesia is associated with sympathetic blockade and subsequent drop in BP specially harmful in a patient with compromised regional circulation due to stenosed arteries. Epidural anaesthesia leads to gradual onset of sympathetic block and decrease in BP.

\section{CONCLUSION}

Several complications can affect pregnancies with TA. Both patients in the present study were young women with different severity who had good perinatal outcome. Mild atonic postpartum haemorrhage and hypertension in our patients were successfully managed. In the management of third stage oxytocics other than oxytocin like PGF2 alpha and methyl ergometrine should be avoided. Intrauterine growth restriction was not present in our cases. Steroid treatment is the main stay of treatment as they suppress systemic symptoms and reverse arterial stenosis. Cytotoxic drugs (methotrexate, azathioprine) to be avoided in pregnancy. Careful patient evaluation, treatment of TA complications, and anaesthetic surgical planning are fundamental. ${ }^{15,16}$ An interdisciplinary collaboration of rheumatologists, cardiologist, nephrologists and obstetricians is necessary to improve maternal and fetal prognosis.

\section{ACKNOWLEDGMENTS}

Authors thank Department of Obstetrics and Gynecology and Department of Cardiology for providing the information.

Funding: No funding sources

Conflict of interest: None declared

Ethical approval: Not required

\section{REFERENCES}

1. Beilin $\mathrm{Y}$, Bernstein $\mathrm{H}$ : Successful epidural anaesthesia for a patient with takayasu's arteritis presenting for Caesarean section. Can J Anaesth. 1993;40:64-6.
2. Ishikawa $\mathrm{K}$, Matsumura S. Occlusive thromboaortopathy (takayasu's disease) and pregnancy. Clinical course and management of 33 pregnancies and deliveries. Am J Cardiol. 1982;50:1293-300.

3. Ioscovich A, Gislason R, Fadeev A. Peripartum anesthetic management of patients with takayasu's arteritis: case series and review. int $\mathrm{J}$ obstet Anesth, 2008;17:358-64.

4. Kathirvel S, Chavan S, Arya VK. Anesthetic management of patients with takayasu's arteritis: a case series and review. Anesth Analg. 2001;93:60-5.

5. Mandal D, Mandal S, Dattaray C, Banerjee D, Ghosh P, Ghosh A, Panja M. Takayasu arteritis in pregnancy: an analysis from eastern India. Archives of gynecology and obstetrics. 2012;285(3):567-71.

6. Matsumura A, Moriwaki R, Numano F. Pregnancy in takayasu arteritis from the view of internal medicine. Heart Vessels. 1992;7:120124.

7. Wilke WS. Large vessel vasculitis (giant cell arteritis, takayasu arteritis). Baillieres Clin Rheumatol. 1997;11:285-313.

8. Ishikawa $\mathrm{K}$, Matsura S. Occlusive thormboaortopathy (Takayasu's disease) and pregnancy: clinical course and management of 33 patients and deliveries. Am J Cardiol. 1982;50:1293300 .

9. Matsumura A, Moriwaki R, Numano F. Pregnancy in Takayasu arteritis from the view of internal medicine. Heart Vessels. 1992;7:20-4.

10. Seo P. Pregnancy and vasculitis. Rheum Dis Clin North Am. 2007;33:299-317.

11. Sharma BK, Sagar S, Singh AP. Takayasu arteritis in India. Heart Vessels. 1992;7:37-43.

12. Liang P, Hoffman GS. Advances in the medical and surgical treatment of takayasu arteritis. Curr opin Rheumatol. 2005;17:16-24.

13. Wong VC, Wang Ry, Tse TF. Pregnancy and takayasu's disease. Am J Med. 1983;75:597-601.

14. Henderson K, Fludder P. Epidural anaesthesia for caesarean section in a patient with severe takayasu's disease. Br J Anaesth. 1999;83:956-9.

15. Papantioniou N, Katsoulis I, Papageorgiou I, Antsaklis A. Takayasu arteritis in pregnancy: safe management options in antenatal care. Case report. Fetal Diagn Ther. 2007;22:449-51.

16. NaliNi S, Santa SA. Takayasu arteritis with bilateral renal artery stenosis and left subclavian artery stenosis in pregnancy. JCDR. 2015;9(9):QD07.

Cite this article as: Upadhya R, Poojari VG, Pai MV, Nambiar J. Successful maternal and fetal outcome in patients with Takayasu arteritis: two case reports of Type I and Type IV in stage 2 . Int J Reprod Contracept Obstet Gynecol 2018;7:759-61. 